\author{
Article \\ Doi 10.5943/mycosphere/8/7/5 \\ Copyright $\odot$ Guizhou Academy of Agricultural Sciences
}

\title{
Effects of additives and bioreactors on cordycepin production from Cordyceps militaris in liquid static culture
}

\author{
Wen TC ${ }^{1,3}$, Long $\mathrm{FY}^{1,3}$, Kang $\mathrm{C}^{2 *}$, Wang $\mathrm{F}^{2}$, Zeng $\mathrm{W}^{1}$ \\ ${ }^{1}$ The Engineering Research Center of Southwest Bio-Pharmaceutical Resources, Ministry of Education, Guizhou \\ University, Guiyang, 550025, Guizhou, China \\ ${ }^{2}$ Institute of Biology, Guizhou Academy of Sciences, Guiyang, 550009, Guizhou Province, China \\ ${ }^{3}$ School of Pharmacy, Guizhou University, Guiyang 550025, Guizhou, China
}

Wen TC, Long FY, Kang C, Wang F, Zeng W 2017 - Effects of additives and bioreactors on cordycepin production from Cordyceps militaris in liquid static culture. Mycosphere 8(7), 886-898, Doi 10.5943/mycosphere/8/7/5

\begin{abstract}
Cordycepin (3'-deoxyadenosine), a nucleoside analog, was isolated from Cordyceps militaris, an entomopathogenic fungus, important in Traditional Chinese Medicine. In this study, Cordycepin production by three strains of $C$. militaris (strains GACP08Y5, GACP08Y1 and GACP0746) in static liquid culture was established using different working volumes and bioreactors. The best cordycepin production of $3005.83 \mathrm{mg} / \mathrm{L}$ was obtained by strain GACP08Y5 in 5 L-flasks, containing $2 \mathrm{~L}$ medium at day 40, and total cordycepin content reached 6011.66 mg/flask. The utilization ratio of adenine reached $91 \%$. This is the highest report of cordycepin production in a single fermenter. This method provides an effective way for increasing the cordycepin production at a large scale. The strategies used in this study could have a wide application in other fermentation processes.
\end{abstract}

Key words - comparison - cordycepin - Cordyceps militaris - Growth curve - large scale production

\section{Introduction}

Cordycepin (3'-deoxyadenosine), a nucleoside analog, was first isolated from Cordyceps militaris (Cunningham et al. 1950), and is one of the most important biologically active metabolites of Cordyceps species. C. militaris, an entomopathogenic fungus belonging to Ascomycota (Sung et al. 2007), has long been used as a Traditional Medicine in China and East Asia (De Silva et al. 2013). Cordycepin has a broad spectrum of biological activity, including anti-cancer (De Silva et al. 2012), anti-tumor (Pao et al. 2012), anti-fungus (Kim et al. 2002), anti-hyperlipidemia (Guo et al. 2010), antioxidant (Ramesh et al. 2012), and anti-leukemia (Thomadaki et al. 2008). Cordycepin is also a Phase I/II clinical stage drug candidate for treatment of refractory Acute Lymphoblastic Leukemia (ALL) patients who express enzyme terminal deoxynucleotidyl transferase (TdT) (ClinicalTrials. Gov, verified by OncoVista, Inc., 2009).

Previous studies have demonstrated that cordycepin could be obtained by chemical synthesis (Aman et al. 2000). However, solid-state fermentation and liquid fermentation are the most popular method to obtain cordycepin. Cordycepin has been extracted from fruiting bodies of $C$. militaris and isolates grown on solid medium (Wen et al. 2014a). In previous studies, it has been shown that formation of fruiting bodies of C. militaris needs a long time (60 days) (Wen et al. 2014a, 2014b), 
and repeated subculturing results in decreased or no fruiting bodies (Shrestha et al. 2012, Wen et al. 2012). The extraction of cordycepin from fruiting bodies or isolates grown on solid medium is also difficult.

In previous reports, liquid fermentation (submerged culture and surface liquid culture / liquid static culture) was considered to be the effective way for obtain cordycepin. The culture requirements of carbon/nitrogen ratio, dissolved oxygen, salts from deep ocean water, amino acids and nucleoside analogues have been investigated with $C$. militaris by submerged culture. Several of these factors were effective components for improved cordycepin production (Hung et al. 2015, Mao \& Zhong 2004, Masuda et al. 2007). Cordycepin has been obtained via surface liquid culture or static liquid culture of strains. The optimum carbon and nitrogen sources, additives and medium depth were studied (Das et al. 2009, Kang et al. 2014, Masuda \& Sakurai 2006). In these reports, $C$. militaris mutant was obtained by a new mutagenesis technique called 'ion beam' (Das et al. 2008). The $C$. militaris mutant G81-3 has higher productivity to produce cordycepin in surface culture, and cordycepin production reached $14300 \mathrm{mg} / \mathrm{L}$ (Masuda et al. 2014). A highest yield of 1405.94 $\mathrm{mg} / \mathrm{L}$ was obtained in a single fermenter $(1000 \mathrm{~mL}$ cylindrical glass bottle containing $700 \mathrm{~mL}$ medium) by static liquid culture (Kang et al. 2014).

The aim of this study was to improve cordycepin production by $C$. militaris in static liquid culture, by adding different additives and using different bioreactors. The working volume in different bioreactor was set for C. militaris strains (GACP08Y5, GACP08Y1, and GACP0746) and the additives were added to the medium at three different times. Cordycepin production per unit volume and total content of cordycepin in the bioreactor was studied simultaneously.

\section{Materials \& Methods}

\section{Microorganism and Seed Culture}

Three different wild-type strains of $C$. militaris, strains GACP08Y5 and GACP08Y1(GACP, the Herbarium of Guizhou Agricultural College, Guiyang, Guizhou, China), collected from Yuse National Forest Park in Guizhou Province and strain GACP0746 collected from Mt. Wawu in Sichuan Province, China were used in this study. Strains were isolated from single ascospores (Wen et al. 2014b). Strains were maintained on potato dextrose agar (PDA) slants, following incubation at $25{ }^{\circ} \mathrm{C}$ for 7 days and then stored at $4{ }^{\circ} \mathrm{C}$. Sterilized distilled water was added to the slant and the asexual spores washed off and then filtered through sterilized absorbent cotton in infundibulum. The spore suspension of $C$. militaris was added to the seed culture medium at a suitable concentration (Wen et al. 2014a). The seed culture was grown in a 250-mL flask containing $70 \mathrm{~mL}$ medium (sucrose $20 \mathrm{~g} / \mathrm{L}$; peptone $20 \mathrm{~g} / \mathrm{L} ; \mathrm{KH}_{2} \mathrm{PO}_{4} 1 \mathrm{~g} / \mathrm{L}$; and $\mathrm{MgSO}_{4} \cdot 7 \mathrm{H}_{2} \mathrm{O} 0.5$ $\mathrm{g} / \mathrm{L} ; \mathrm{pH}$ natural) at $25^{\circ} \mathrm{C}$ on a rotary shaker incubator at $150 \mathrm{r} / \mathrm{min}$ for 5 days (Kang et al. 2014).

\section{Static liquid culture, medium and additives}

The medium of static liquid culture for $C$. militaris comprised sucrose $20 \mathrm{~g} / \mathrm{L}$, peptone $20 \mathrm{~g} / \mathrm{L}$ and $\mathrm{KH}_{2} \mathrm{PO}_{4} 1 \mathrm{~g} / \mathrm{L} ; \mathrm{MgSO}_{4} \cdot 7 \mathrm{H}_{2} \mathrm{O} 0.5 \mathrm{~g} / \mathrm{L}$. The $\mathrm{pH}$ was natural, followed by autoclaving for $30 \mathrm{~min}$ at $121{ }^{\circ} \mathrm{C}$. The static culture experiments were performed in $3 \mathrm{~L}$-flasks, containing $2 \mathrm{~L}$ of media (2 $\mathrm{L} / 3 \mathrm{~L} ; \mathrm{v} / \mathrm{v}), 5 \mathrm{~L}$-flasks containing $2 \mathrm{~L}, 3 \mathrm{~L}$, and $4 \mathrm{~L}$ of media $(2 \mathrm{~L} / 5 \mathrm{~L}, 3 \mathrm{~L} / 5 \mathrm{~L}$ and $4 \mathrm{~L} / 5 \mathrm{~L}$; v/v), $370 \mathrm{~mL}-c y l i n d r i c a l$ glass bottles (inner diameter $70 \mathrm{~mm}$ and height $120 \mathrm{~mm}$ ) containing $300 \mathrm{~mL}$ of media $(300 \mathrm{~mL} / 370 \mathrm{~mL} ; \mathrm{v} / \mathrm{v})$ and $480 \mathrm{~mL}$ cylindrical glass bottles (inner diameter $80 \mathrm{~mm}$ and height $120 \mathrm{~mm}$ ) containing $400 \mathrm{~mL}$ of media $(400 \mathrm{~mL} / 480 \mathrm{~mL} ; \mathrm{v} / \mathrm{v})$. The inoculated flasks were sealed with a cotton plug and the bottles sealed by a film of polypropylene plastic. The static liquid culture was started by inoculating the liquid seed with $10 \%(\mathrm{v} / \mathrm{v}$; the biomass dry weight of seed culture is $54 \mathrm{mg} / \mathrm{mL}$ ) into bioreactors and incubated at $25^{\circ} \mathrm{C}$ for 52 days. Adenine $1 \mathrm{~g} / \mathrm{L}$ and glycine $16 \mathrm{~g} / \mathrm{L}$ were added to the medium at 4,10 , and 30 days.

\section{Analytical methods}

For the analysis of effects of adenine on cordycepin production, all samples collected at 52 
days from different culture bottles were centrifuged at $2810 \times \mathrm{g}$ for $20 \mathrm{~min}$. The supernatant was filtered through a $0.45 \mu \mathrm{m}$ membrane and the filtrate was analyzed by high-performance liquid chromatography (1100 series, Agilent Technology, U.S.). Standard adenine and cordycepin (Sigma,

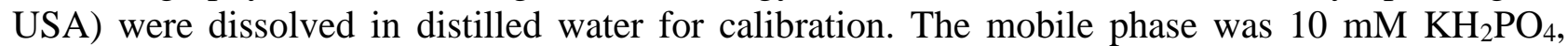
which was dissolved in methanol/distilled water (6:94). Elution was performed at a flow rate of 1.0 $\mathrm{mL} / \mathrm{min}$ with column temperature at $45^{\circ} \mathrm{C}$ and UV wavelength of $259 \mathrm{~nm}$ (Kang et al. 2014, Wen et al. 2014a). All figures were formed by OriginPro 8.5.0 SR1 b161 software package (OriginLab Corporation, Northampton, USA).

\section{Results}

\section{Effects of working volume and additives on cordycepin production for strain GACP08Y5 Effects of $2 \mathrm{~L} / 3 \mathrm{~L}$ on cordycepin production}

The influence of $2 \mathrm{~L} / 3 \mathrm{~L}$ bioreactors on cordycepin production by $C$. militaris was studied in static liquid culture for strain GACP08Y5. As shown in Figure 1b, the production of cordycepin increased gradually with cultivation time from 0 to 52 days. The maximal cordycepin production reached $2402.78 \mathrm{mg} / \mathrm{L}$ on day 52 , and this value was 7.3 times higher than control $(328.57 \mathrm{mg} / \mathrm{L}$ on day 52). Production of cordycepin increased rapidly at 2 - 4 days later with the addition of adenine $1 \mathrm{~g} / \mathrm{L}$ and glycine $16 \mathrm{~g} / \mathrm{L}$. In Figure $1 \mathrm{a}$ and $1 \mathrm{~b}$, the $\mathrm{pH}$ value of medium decreased firstly from 0 to 6 days, and then increased slowly from 6 to 52 days. There were three peaks of adenosine concentration were found at 8,36 , and 48 days in experimental group. From Figure $1 \mathrm{~b}$, adenine concentration was decreased rapidly at later with adding adenine $1 \mathrm{~g} / \mathrm{L}$ and glycine $16 \mathrm{~g} / \mathrm{L}$. At the end of the fermentation process, residual adenine concentration in the media was $673.03 \mathrm{mg} / \mathrm{L}$, and the utilization ratio of adenine ( $(3 \mathrm{~g} / \mathrm{L}-$ residual adenine concentration $) / 3 \mathrm{~g} / \mathrm{L} \times 100 \%)$ reached $77.57 \%$. The change of adenine concentration shows " $\mathrm{A}$ " form in control group (Figure 1a), and the maximal concentration of adenine was reached $11.23 \mathrm{mg} / \mathrm{L}$ at day 26.
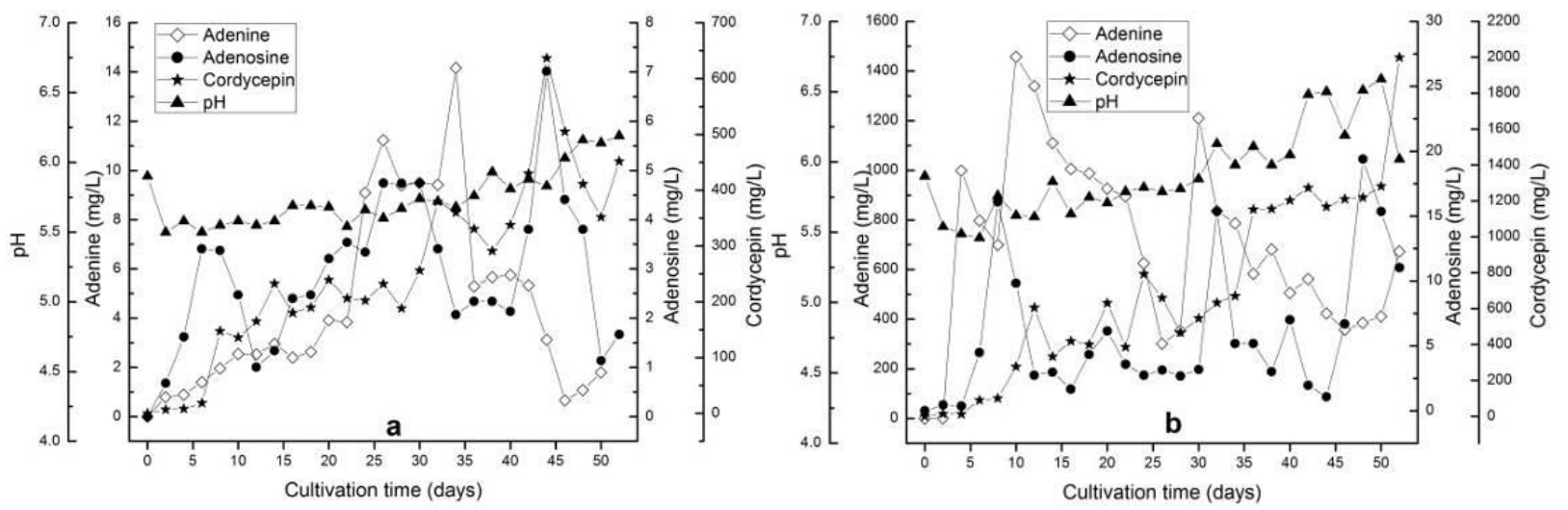

Figure 1 - Effects of 3L-flasks containing 2L medium on cordycepin production for strain GACP08Y5 (a: Control group; b: Experimental group).

\section{Effects of working volume in 5 L-flasks on cordycepin production}

In order to evaluate the influence of working volume on cordycepin production, $2 \mathrm{~L}, 3 \mathrm{~L}$, and $4 \mathrm{~L}$ of media were fermented in 5 L-flasks (Figure 2, 3, and 4). Cordycepin production increased gradually from 0 to 40 days, and then decreased slowly from 40 to 52 days (Figure $2 \mathrm{~b}$ ). And in Figure $2 \mathrm{~b}$ and $3 \mathrm{~b}$, the cordycepin production was increased until 52 days. The maximal cordycepin production reached $3005.83 \mathrm{mg} / \mathrm{L}$ on day $40,1391.00 \mathrm{mg} / \mathrm{L}$ on day 52 , and $895.79 \mathrm{mg} / \mathrm{L}$ on day 52 in $2 \mathrm{~L}, 3 \mathrm{~L}$, and $4 \mathrm{~L}$ of medium, respectively. From Figure $2 \mathrm{~b}$, and $3 \mathrm{~b}$, the $\mathrm{pH}$ value of media decreased firstly, and then increased. However, in Figure $4 \mathrm{~b}$, the $\mathrm{pH}$ value reduced gradually until end of the fermentation process. And we found the ultimate $\mathrm{pH}$ values were reduced from 7.36 to 5.27 in three tests. Adenosine concentration was increased rapidly at $2-4$ days later with adding 
adenine $1 \mathrm{~g} / \mathrm{L}$ and glycine $16 \mathrm{~g} / \mathrm{L}$ in Figure $2 \mathrm{~b}, 3 \mathrm{~b}$, and $4 \mathrm{~b}$. Subsequently, they were reduced rapidly. Especially, there was a peak of adenosine concentration at 48 or 50 day, and there was positive correlation between adenosine concentration and working volume. Adenine concentration was reduced rapidly at later with adding adenine $1 \mathrm{~g} / \mathrm{L}$ and glycine $16 \mathrm{~g} / \mathrm{L}$ (Figure $2 \mathrm{~b}, 3 \mathrm{~b}$, and $4 \mathrm{~b}$ ). Residual adenine concentration in medium were $245.64 \mathrm{mg} / \mathrm{L}, 888.51 \mathrm{mg} / \mathrm{L}$ and $537.26 \mathrm{mg} / \mathrm{L}$ at time of the maximal cordycepin production, and the utilization ratio of adenine reached $91.81 \%$, $70.38 \%$, and $82.09 \%$ respectively. The change of adenine concentration shows " $\mathrm{A}$ " form in control group (Figure 2a, 3a, and 3a), and the highest concentration of adenine were reached $5.00 \mathrm{mg} / \mathrm{L}$, $5.50 \mathrm{mg} / \mathrm{L}$, and $13.10 \mathrm{mg} / \mathrm{L}$ at day 24,30 , and 26 respectively.
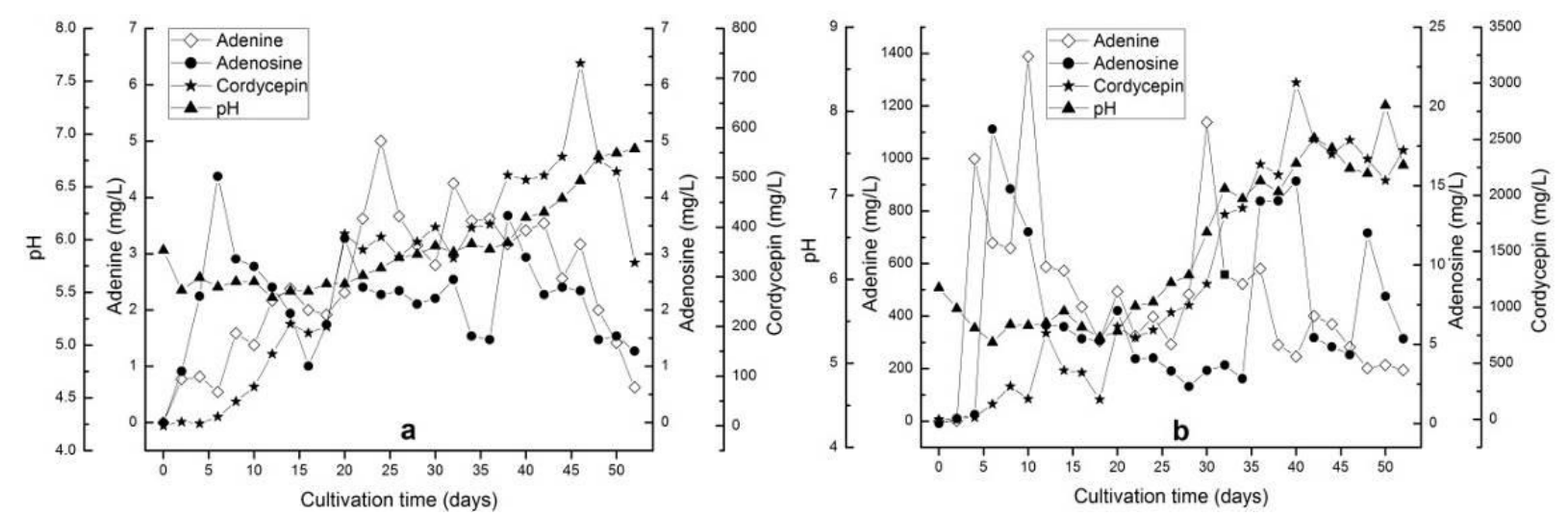

Figure 2 - Effects of 5 L-flasks containing 2 L medium on cordycepin production for strain GACP08Y5 (a: Control group; b: Experimental group).
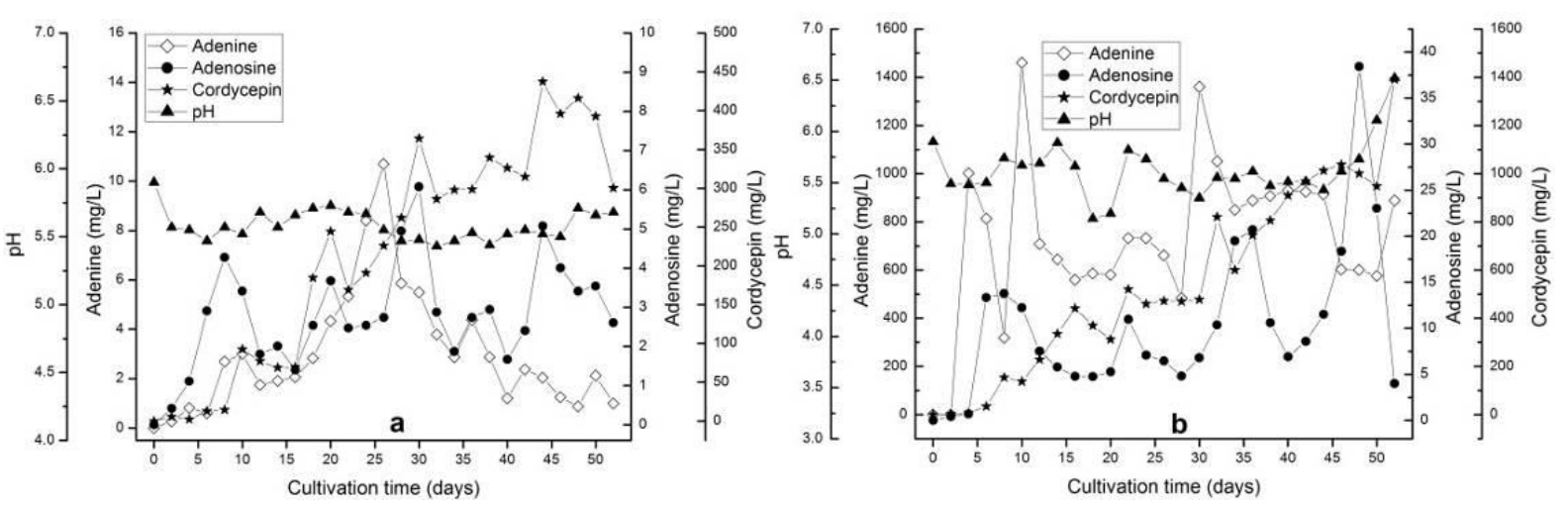

Figure 3 - Effects of 5 L-flasks containing $3 \mathrm{~L}$ medium on cordycepin production for strain GACP08Y5 (a: Control group; b: Experimental group).
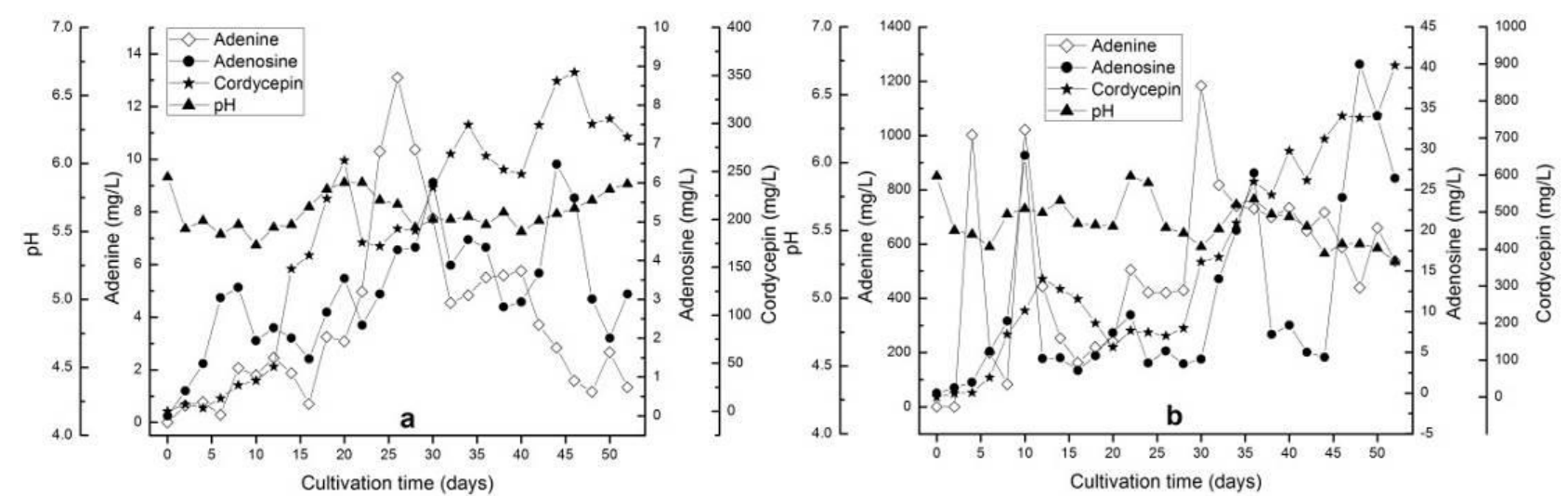

Figure 4 - Effects of 5 L-flasks containing $4 \mathrm{~L}$ medium on cordycepin production for strain GACP08Y5 (a: Control group; b: Experimental group). 


\section{Effects of $300 \mathrm{~mL} / 370 \mathrm{~mL}$ and additives on cordycepin production}

In this study, $370 \mathrm{~mL}$-cylindrical glass bottles containing $300 \mathrm{~mL}$ medium was studied on cordycepin production for strain GACP08Y5. As shown in Figure 5b, the cordycepin production increased gradually with cultivation time from 0 to 50 days. The result showed that the maximum cordycepin production of $2241.50 \mathrm{mg} / \mathrm{L}$ was achieved at day 50 , and this value was 3.7 times than control group $(605.23 \mathrm{mg} / \mathrm{L}$ on day 50$)$. But cordycepin production was reduced slightly at day 52 . From Figure $5 \mathrm{~b}$, the $\mathrm{pH}$ value of media decreased firstly from 5.9 to 4.81 , and then increased rapidly from 4.81 to 8.24 . In control group, the changing curve of $\mathrm{pH}$ value was similar to experimental group (Figure 5a, and 5b). In the same time, we found that the ultimate $\mathrm{pH}$ value was higher than initial in experimental group, but the control group was opposite. Adenosine concentration was increased rapidly later with adding adenine $1 \mathrm{~g} / \mathrm{L}$ and glycine $16 \mathrm{~g} / \mathrm{L}$, and then decreased rapidly in Figure $5 \mathrm{~b}$. Residual adenine concentration in medium was $802.76 \mathrm{mg} / \mathrm{L}$ at time of the maximal cordycepin production, and the utilization ratio of adenine reached $73.24 \%$. The change of adenine concentration shows "A" form in control group (Figure 5a), and the maximal concentration of adenine was reached $8.10 \mathrm{mg} / \mathrm{L}$ at day 24 .
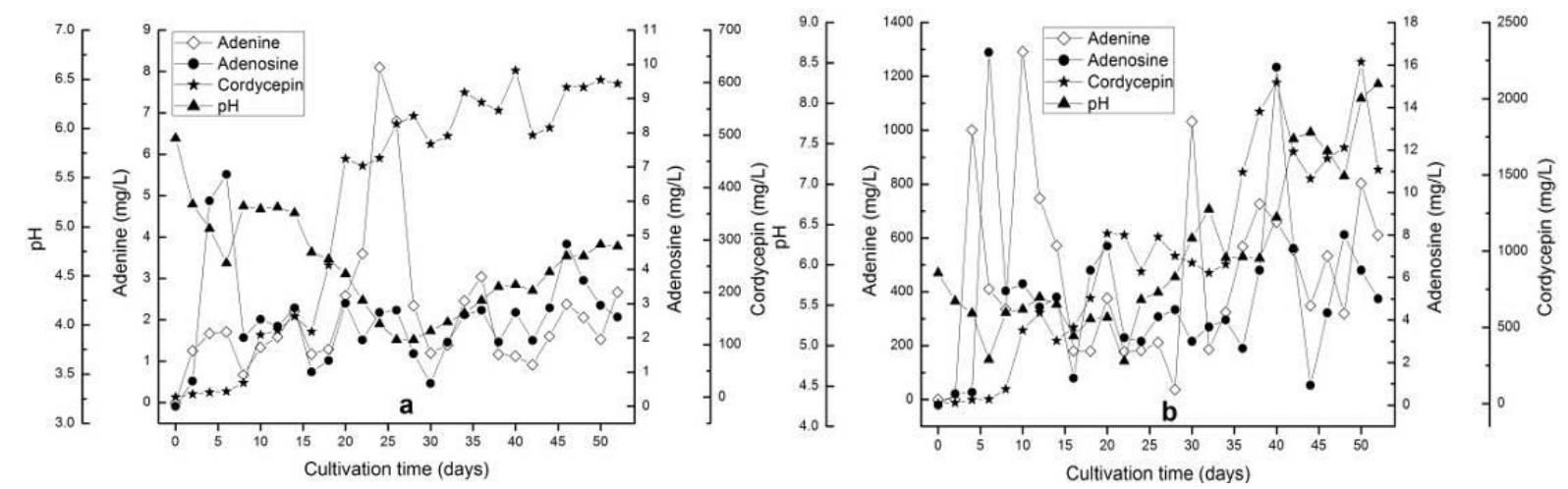

Figure 5 - Effects of $370 \mathrm{~mL}$-cylindrical glass bottles containing $300 \mathrm{~mL}$ medium on cordycepin production for strain GACP08Y5 (a: Control group; b: Experimental group).

\section{Effects of $400 \mathrm{~mL} / 480 \mathrm{~mL}$ and additives on cordycepin production}

In this experiment, $480 \mathrm{~mL}$-cylindrical glass bottles containing $400 \mathrm{~mL}$ medium was investigated on cordycepin production for strain GACP08Y5. Our results demonstrated that the cordycepin production was increased gradually with cultivation time from 0 to 52 days. The maximum yield of cordycepin production reached $2440.89 \mathrm{mg} / \mathrm{L}$ at day 52 , and this value was 4.98 times than control group (491.00 $\mathrm{mg} / \mathrm{L}$ on day 52) (Figure 6b). The results showed there were differences in cordycepin production of experimental group and control group. The maximum cordycepin production was achieved at day 46 and not day 52 in control group (Figure 6a). The $\mathrm{pH}$ value of media decreased firstly, and then increased gradually (Figure 6a and 6b). And the ultimate $\mathrm{pH}$ values reached 8.14 at day 52 in experimental group (Figure 6b). Adenosine concentration was increased rapidly later with adding adenine $1 \mathrm{~g} / \mathrm{L}$ and glycine $16 \mathrm{~g} / \mathrm{L}$, and then decreased rapidly in Figure 6b. Residual adenine concentration in medium was $561.53 \mathrm{mg} / \mathrm{L}$ at day 52 , and the utilization ratio of adenine reached $81.28 \%$. The change of adenine concentration shows " $\mathrm{N}$ " form in control group (Figure 6a), and the maximal concentration of adenine was reached $3.30 \mathrm{mg} / \mathrm{L}$ at day 52.

\section{Effects of working volume and additives on cordycepin production for strain GACP08Y1 Effects of $2 \mathrm{~L} / 3 \mathrm{~L}$ and additives on cordycepin production}

To examine the effect of working volume and additives on the production of cordycepin, $3 \mathrm{~L}$ flask containing $2 \mathrm{~L}$ medium were used for cultivation of $C$. militaris GACP08Y1 strains. As shown in Figure $7 \mathrm{~b}$, the cordycepin production increased gradually with cultivation time from 0 to 42 days, and then decreased slowly from 42 to 52 days. The maximum cordycepin production of 
$2705.8 \mathrm{mg} / \mathrm{L}$ was achieved, and this value was 1.77 times than control group $(1530.15 \mathrm{mg} / \mathrm{L}$ on day 42). However, the maximum cordycepin production was achieved at day 48 and not day 52 in control group (Figure 7a). In experimental group, the $\mathrm{pH}$ value of media was decreased firstly, and then increased gradually. Nevertheless, it was decreased gradually until end of the fermentation process in control group. The adenine concentration was decreased rapidly later with adding additives (Figure $7 \mathrm{~b}$ ). Residual adenine concentration in medium was $446.71 \mathrm{mg} / \mathrm{L}$ at day 52, and the utilization ratio of adenine reached $85.11 \%$. The change of adenine concentration shows "A" form in control group (Figure 7a), and the maximal concentration of adenine was reached 14.46 $\mathrm{mg} / \mathrm{L}$ at day 18 .
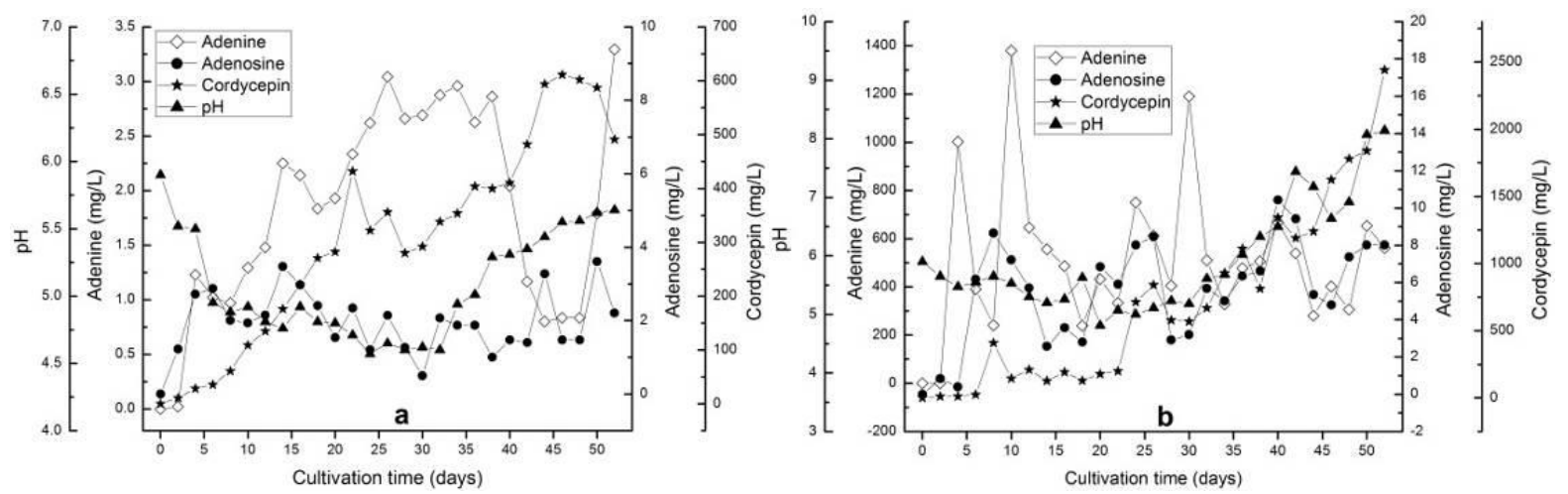

Figure 6 - Effects of $480 \mathrm{~mL}$-cylindrical glass bottles containing $400 \mathrm{~mL}$ medium on cordycepin production for strain GACP08Y5 (a: Control group; b: Experimental group).
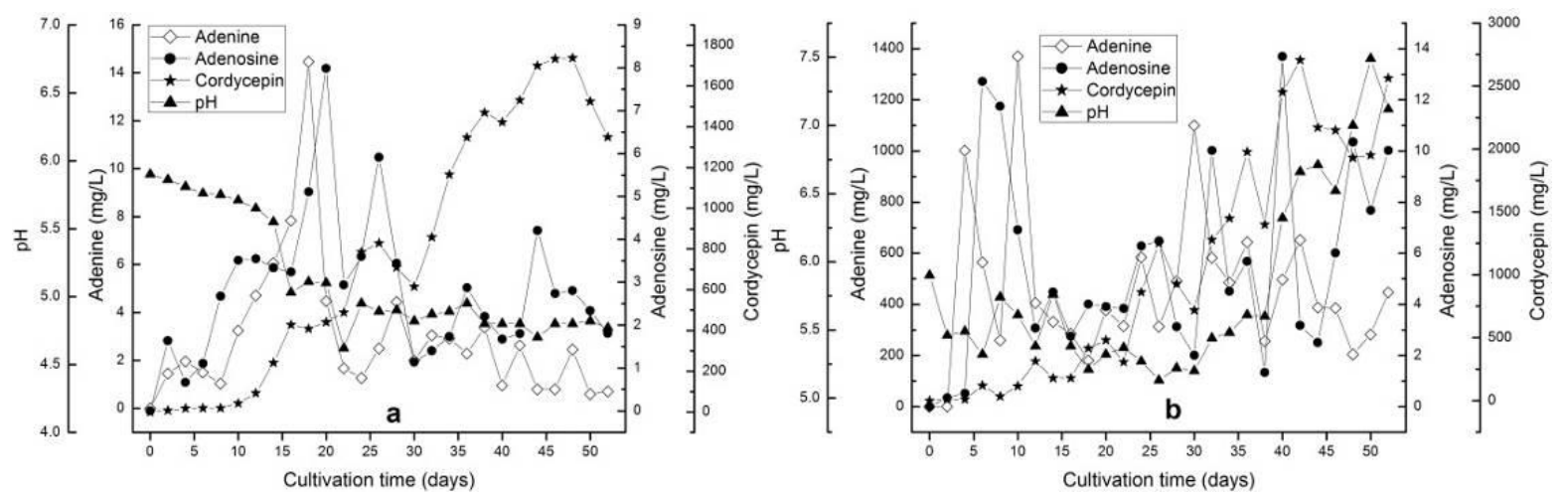

Figure 7 - Effects of 3 L-flasks containing 2 L medium on cordycepin production for strain GACP08Y1 (a: Control group; b: Experimental group).

\section{Effects of $300 \mathrm{~mL} / 370 \mathrm{~mL}$ and additives on cordycepin production}

To investigate the influence of working volume and additives on the production of cordycepin, the fungus of $C$. militaris GACP08Y1 strains was cultivated in medium of $370 \mathrm{~mL}-$ cylindrical glass bottles containing $300 \mathrm{~mL}$ medium. As shown in Figure 8b, the cordycepin production increased gradually until day 52 . The highest cordycepin production of $4008.32 \mathrm{mg} / \mathrm{L}$ was obtained, and this value was 3.96 times than control group $(1011.29 \mathrm{mg} / \mathrm{L})$ on day 52 . However, the highest cordycepin production $1304.02 \mathrm{mg} / \mathrm{L}$ was achieved at day 44 and not day 52 in control group (Figure 8a). From Figure 8b, the $\mathrm{pH}$ value of media was decreased firstly, and then increased rapidly. Nevertheless, it was decreased gradually until end of the fermentation process in control group. The adenine concentration was decreased rapidly later with adding adenine $1 \mathrm{~g} / \mathrm{L}$ and glycine $16 \mathrm{~g} / \mathrm{L}$ (Figure 8b). Residual adenine concentration in medium was $402.00 \mathrm{mg} / \mathrm{L}$ at day 52 , and the utilization ratio of adenine reached $86.6 \%$. The change of adenine concentration shows "M" form in control group (Figure 8a), and two peaks of adenine concentration were found at 14 and 36 days. 

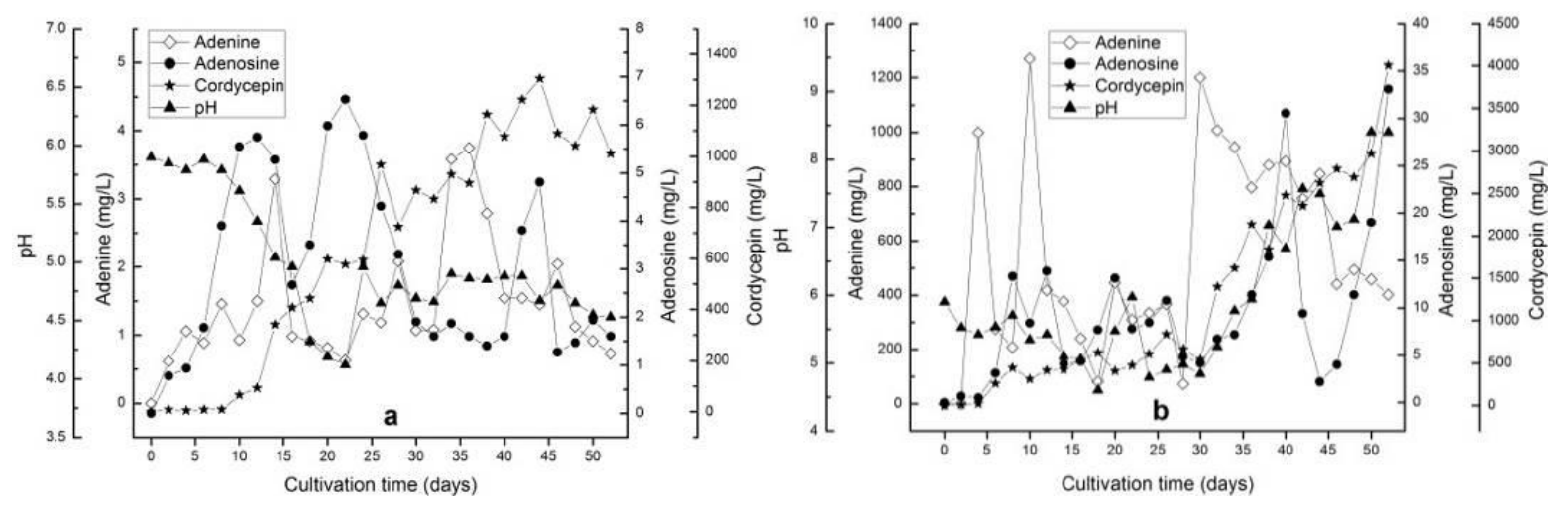

Figure 8 - Effects of $370 \mathrm{~mL}-c y l i n d r i c a l$ glass bottles containing $300 \mathrm{~mL}$ medium on cordycepin production for strain GACP08Y1 (a: Control group; b: Experimental group).

\section{Effects of $400 \mathrm{~mL} / 480 \mathrm{~mL}$ and additives on cordycepin production}

In this study, $480 \mathrm{~mL}$-cylindrical glass bottles containing $400 \mathrm{~mL}$ medium was examined on cordycepin production for strain GACP08Y1. As shown in Figure 9b, the cordycepin production increased rapidly with cultivation time from 0 to 40 days, and then decreased slowly from 40 to 52 days. The maximum cordycepin production of $4376.96 \mathrm{mg} / \mathrm{L}$ was achieved at day 46 . In control group, the tendency of cordycepin production was similar to experimental group. However, the maximum cordycepin production was obtained at day 44, and then decreased rapidly. From Figure $9 \mathrm{~b}$, the $\mathrm{pH}$ value of media decreased firstly from 5.9 to 4.16 , and then increased rapidly from 4.16 to 8.02. In control group, the changing curve of $\mathrm{pH}$ value was similar to experimental group (Figure $9 \mathrm{a}$, and $9 \mathrm{~b}$ ). In the same time, we found that the ultimate $\mathrm{pH}$ value was higher than initial in experimental group, but the control group was opposite. Adenosine concentration was increased rapidly later with adding adenine $1 \mathrm{~g} / \mathrm{L}$ and glycine $16 \mathrm{~g} / \mathrm{L}$, and then decreased rapidly in Figure $9 \mathrm{~b}$. Residual adenine concentration in medium was $177.24 \mathrm{mg} / \mathrm{L}$ at time of the maximal cordycepin production, and the utilization ratio of adenine reached $94.09 \%$. The change of adenine concentration was fluctuation (Figure 9a), and the maximal concentration of adenine was reached $4.04 \mathrm{mg} / \mathrm{L}$ at day 48 .
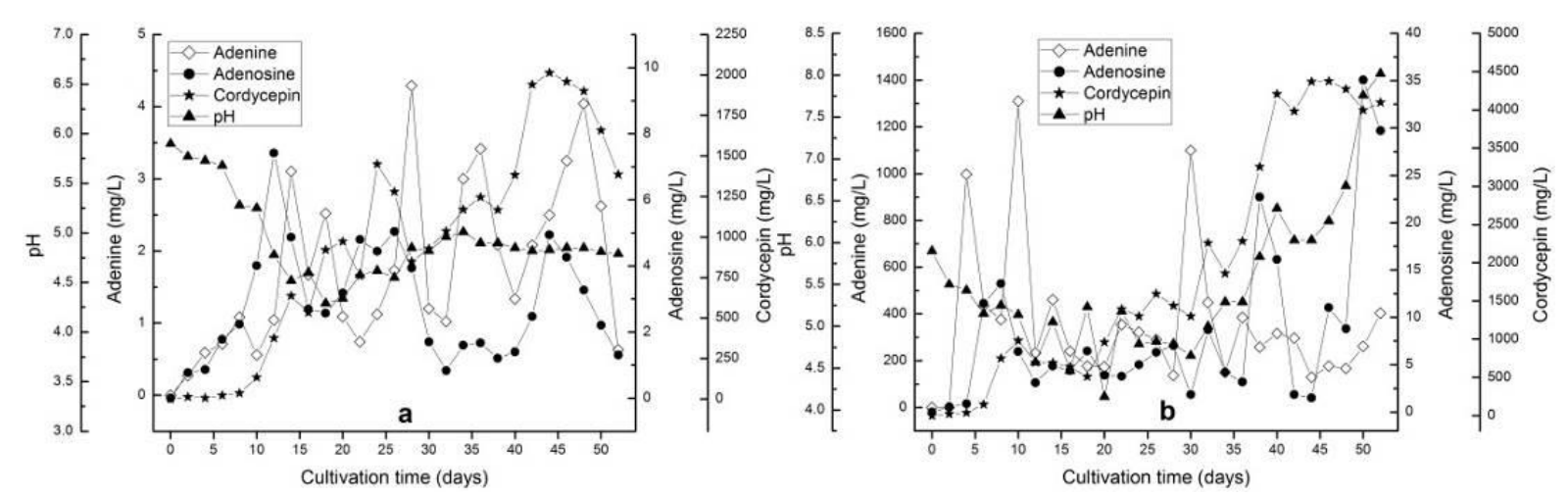

Figure 9 - Effects of $480 \mathrm{~mL}$-cylindrical glass bottles containing $400 \mathrm{~mL}$ medium on cordycepin production for strain GACP08Y1 (a: Control group; b: Experimental group).

\section{Effects of working volume and additives on cordycepin production for strain GACP0746 Effects of $2 \mathrm{~L} / 3 \mathrm{~L}$ and additives on cordycepin production}

In this experiment, 3 L-flasks containing $2 \mathrm{~L}$ medium was investigated on cordycepin production for strain GACP0746. The results demonstrated that the cordycepin production increased gradually with cultivation time from 0 to 40 days, and then decreased from 40 to 46 days, and increased gradually at the end of the fermentation process (from 46 to 52 days). The highest yield of cordycepin production reached $2143.11 \mathrm{mg} / \mathrm{L}$ at day 52 (Figure 10b). The changing curve 
of cordycepin production shows " $\mathrm{M}$ " form in control, and two peaks of cordycepin production were found at 24 and 45 days, respectively. The highest yield of cordycepin production was $460.51 \mathrm{mg} / \mathrm{L}$ at day 45 (Figure 10a). There were was similar change about the $\mathrm{pH}$ value of media in experimental group and control group (Figure 10a and 10b). They were decreased firstly, and then increased slowly respectively. Adenosine concentration was increased rapidly later with adding adenine $1 \mathrm{~g} / \mathrm{L}$ and glycine $16 \mathrm{~g} / \mathrm{L}$, and then decreased rapidly in Figure 10b. Adenine was added to the medium as additive at 4, 10, and 30 days. As shown in Figure 10b, concentration of adenine was decreased rapidly at later with adding adenine $1 \mathrm{~g} / \mathrm{L}$ and glycine $16 \mathrm{~g} / \mathrm{L}$. The residual adenine concentration in medium was $170 \mathrm{mg} / \mathrm{L}$ at day 52, and the utilization ratio of adenine reached $94.33 \%$. The change of adenine concentration was fluctuation (Figure 10a), and approximate "A" form. The maximal concentration of adenine was reached $2.96 \mathrm{mg} / \mathrm{L}$ at day 46.
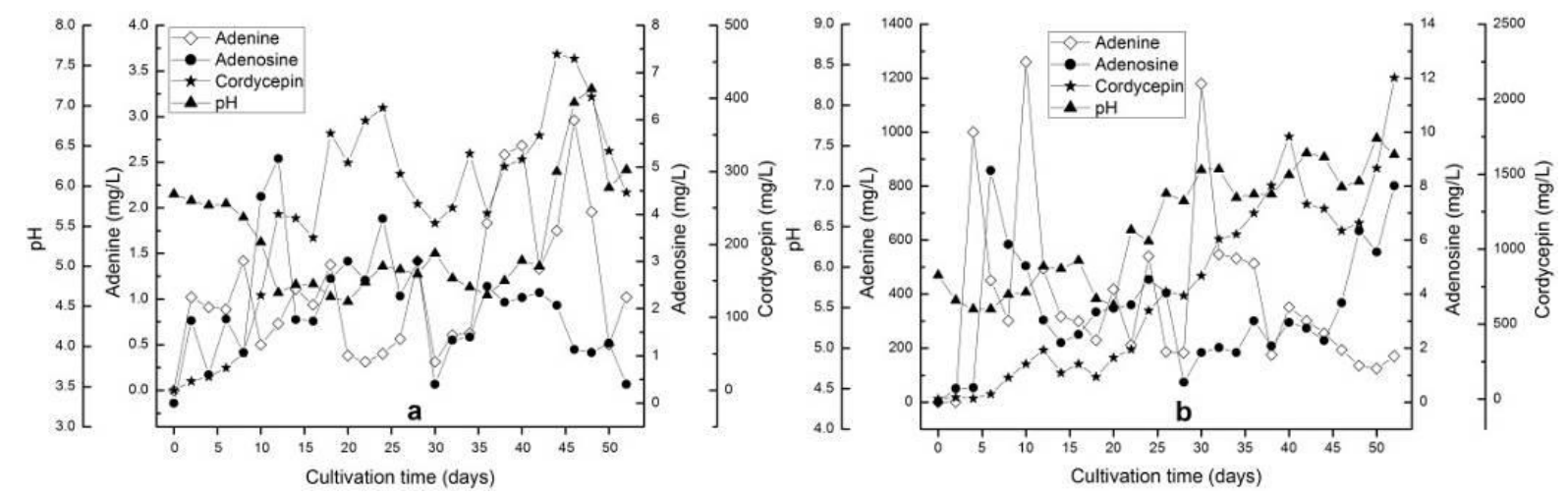

Figure 10 - Effects of 3L-flasks containing 2L medium on cordycepin production for strain GACP0746 (a: Control group; b: Experimental group).

\section{Effects of $300 \mathrm{~mL} / 370 \mathrm{~mL}$ and additives on cordycepin production}

In this test, $370 \mathrm{~mL}$-cylindrical glass bottles containing $300 \mathrm{~mL}$ medium was investigated for cordycepin production using strain GACP0746. As shown in Figure 11b, the cordycepin production increased gradually with cultivation from 0 to 50 days. The highest yield of cordycepin reached $2346.09 \mathrm{mg} / \mathrm{L}$. There were differences between the experimental group and control group. The peak of cordycepin production was at 44 days, and then decreased in the control group (Figure 11a). The $\mathrm{pH}$ value of media first decreased, and then increased in both the experimental group and control group (Figure 11a and 11b). The optimal pH value was higher than initial in experimental group, but the control group was opposite. Adenosine concentration was increased rapidly later with adding adenine $1 \mathrm{~g} / \mathrm{L}$ and glycine $16 \mathrm{~g} / \mathrm{L}$, and shows " $\mathrm{N}$ " form in experimental group (Figure $11 \mathrm{~b})$. From Figure 11b, concentration of adenine was decreased rapidly at later with adding adenine $1 \mathrm{~g} / \mathrm{L}$ and glycine $16 \mathrm{~g} / \mathrm{L}$. The residual adenine concentration in medium was $369.49 \mathrm{mg} / \mathrm{L}$ at day 50 , and the utilization ratio of adenine reached $87.68 \%$. The change of adenine concentration shows "M" form in control group (Figure 11a), and two peaks of adenine concentration were found at 14 and 21 days.

\section{Effects of $400 \mathrm{~mL} / 480 \mathrm{~mL}$ and additives on cordycepin production}

To investigate the effect of working volume on the production of cordycepin, C. militaris strain GACP0746 was cultivated in $480 \mathrm{~mL}$-cylindrical glass bottles containing $400 \mathrm{~mL}$ media. Cordycepin production increased gradually until day 52 (Figure 12b). The highest cordycepin production of $2828.12 \mathrm{mg} / \mathrm{L}$ was obtained on day 52, and this value was 3.96 times than control group $(505.69 \mathrm{mg} / \mathrm{L})$. However, the highest cordycepin production of $790.09 \mathrm{mg} / \mathrm{L}$ was achieved at day 46 and not day 52 in the control group (Figure 12a). From Figure 12b, the pH value of media was first decreased, and then increased rapidly. However, the $\mathrm{pH}$ decreased gradually until end of the fermentation process in the control group. Adenosine concentration was increased rapidly later with adding additives. The adenine concentration was decreased rapidly later with adding adenine 1 
$\mathrm{g} / \mathrm{L}$ and glycine $16 \mathrm{~g} / \mathrm{L}$ (Figure 12b). Residual adenine concentration in medium was $558.2 \mathrm{mg} / \mathrm{L}$ at day 52, and the utilization ratio of adenine reached $81.39 \%$. The change of adenine concentration shows " $M$ " form in control group (Figure 12a), and two peaks of adenine concentration were found at 14 and 32 days.
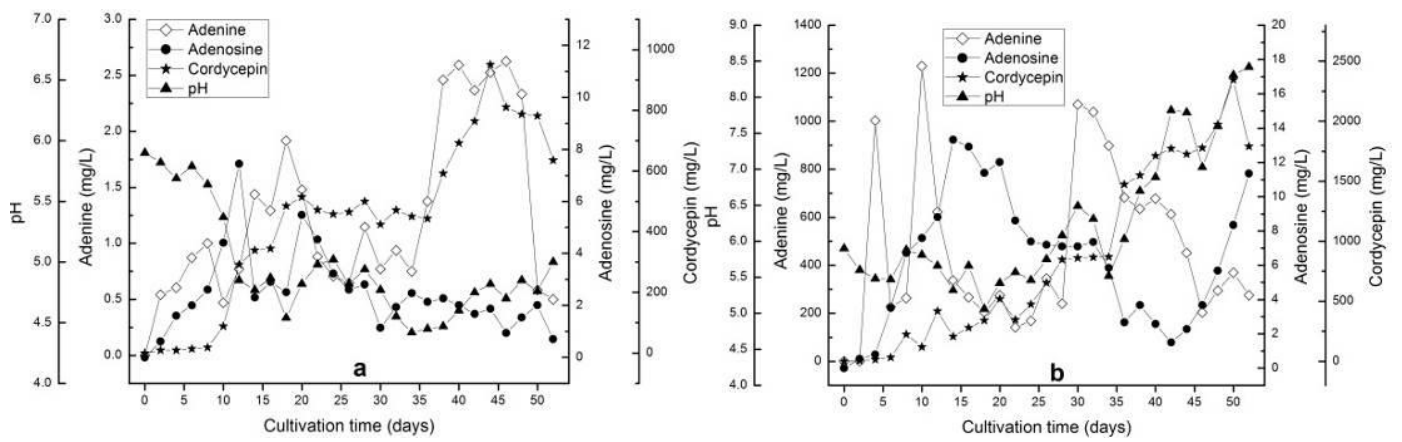

Figure 11 - Effects of $370 \mathrm{~mL}$-cylindrical glass bottles containing $300 \mathrm{~mL}$ medium on cordycepin production for strain GACP0746 (a: Control group; b: Experimental group).
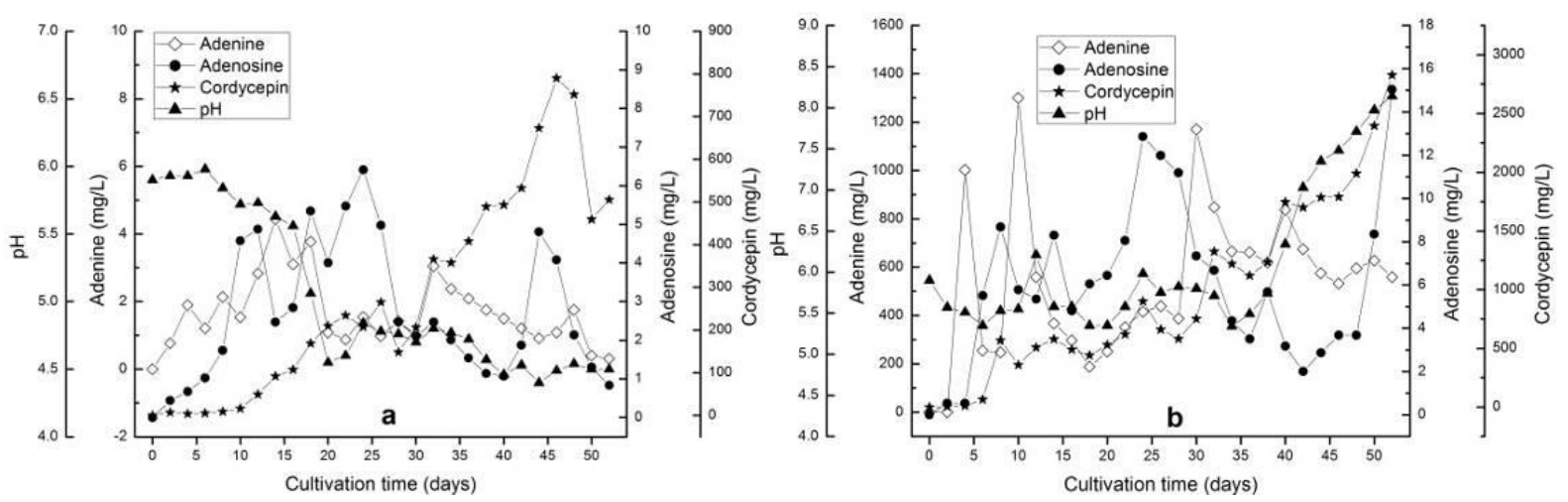

Figure 12 - Effects of $480 \mathrm{~mL}$-cylindrical glass bottles containing $400 \mathrm{~mL}$ medium on cordycepin production for strain GACP0746 (a: Control group; b: Experimental group).

\section{Cordycepin production and adenine concentrations in different bioreactors}

We compared the differences in cordycepin production, total cordycepin content, adenine concentration, adenine utilization ratio, and cultivation time by adding additives in the different static liquid bioreactors (Table 1). The maximum cordycepin production of $3005.83 \mathrm{mg} / \mathrm{L}$ was obtained for $C$. militaris strain GACP08Y5 when adding adenine $1 \mathrm{~g} / \mathrm{L}$ and glycine $16 \mathrm{~g} / \mathrm{L}$ in $5 \mathrm{~L}-$ flasks containing $2 \mathrm{~L}$ medium at day 40. The total content of cordycepin reached $6011.66 \mathrm{mg}$, and utilization ratio of adenine reached $91.81 \%$. Cordycepin production by $C$. militaris strain GACP08Y1, reached a maximum of $4376.96 \mathrm{mg} / \mathrm{L}$ in $480 \mathrm{~mL}$-cylindrical glass bottles containing $400 \mathrm{~mL}$ medium at day 46, and utilization ratio of adenine reached $94.09 \%$ and was the highest cordycepin production in this study. The maximum total content of cordycepin reached $5127.44 \mathrm{mg}$ in $3 \mathrm{~L}$-flask containing $2 \mathrm{~L}$ medium at day 40 . The maximum cordycepin production by $C$. militaris strain GACP0746 reached $2828.12 \mathrm{mg} / \mathrm{L}$ in $480 \mathrm{~mL}$-cylindrical glass bottles containing $400 \mathrm{~mL}$ medium at day 52. However, the maximum total content of cordycepin reached $4286.22 \mathrm{mg}$ in $5 \mathrm{~L}-$ flasks containing $2 \mathrm{~L}$ medium at day 52. $480 \mathrm{~mL}$-cylindrical glass bottles containing $400 \mathrm{~mL}$ medium increased cordycepin production per unit volume for three strains (GACP08Y5, GACP08Y1 and GACP0746).

Nevertheless, $2 \mathrm{~L}$ of media in $5 \mathrm{~L}$-flask was an effective working volume for total content of cordycepin. In conclusion, $5 \mathrm{~L}$-flasks containing $2 \mathrm{~L}$ with adenine $1 \mathrm{~g} / \mathrm{L}$ and glycine $16 \mathrm{~g} / \mathrm{L}$ by $C$. militaris strain GACP08Y5 was the optimal culture method in static liquid culture. Furthermore, 5 L-flasks containing $2 \mathrm{~L}$ for $C$. militaris GACP08Y1 was also considered auxiliary cultural method. 
Table 1. Cordycepin production in different bioreactors ${ }^{\text {a }}$

\begin{tabular}{|c|c|c|c|c|c|c|c|c|}
\hline \multirow{2}{*}{ Strains } & \multirow{2}{*}{$\begin{array}{l}\text { Working } \\
\text { volume of } \\
\text { the } \\
\text { medium } \\
(\mathrm{v} / \mathrm{v})^{\mathrm{b}}\end{array}$} & \multirow{2}{*}{ 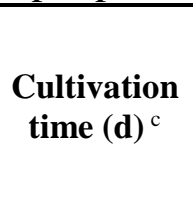 } & \multicolumn{2}{|c|}{$\begin{array}{c}\text { Cordycepin production } \\
(\mathrm{mg} / \mathrm{L})\end{array}$} & \multicolumn{2}{|c|}{$\begin{array}{c}\text { Total content of } \\
\text { cordycepin }(\mathbf{m g})^{\mathrm{e}}\end{array}$} & \multirow{2}{*}{$\begin{array}{c}\text { Residual } \\
\text { adenine } \\
\text { concentration } \\
(\mathrm{mg} / \mathrm{L})\end{array}$} & \multirow{2}{*}{$\begin{array}{l}\text { Utilization } \\
\text { ratio of } \\
\text { adenine } \\
(\%)^{\mathrm{f}}\end{array}$} \\
\hline & & & Control & Experimental $^{\mathrm{d}}$ & Control & Experimental & & \\
\hline \multirow{6}{*}{ GACP08Y5 } & $2 / 3$ & 52 & 328.57 & 2402.78 & 657.14 & 4805.56 & 673.03 & 77.57 \\
\hline & $2 / 5$ & 40 & 495.26 & 3005.83 & 990.52 & 6011.66 & 245.64 & 91.81 \\
\hline & $3 / 5$ & 52 & 328.57 & 1391.00 & 985.71 & 4173.00 & 888.51 & 70.38 \\
\hline & $4 / 5$ & 52 & 286.12 & 895.79 & 1144.48 & 3583.16 & 537.26 & 82.09 \\
\hline & $300 / 370$ & 50 & 605.23 & 2241.50 & 181.57 & 672.45 & 802.76 & 73.24 \\
\hline & $400 / 480$ & 52 & 491.00 & 2440.89 & 235.68 & 1171.63 & 561.53 & 81.28 \\
\hline \multirow{3}{*}{ GACP08Y1 } & $2 / 3$ & 52 & 1349.42 & 2563.72 & 2698.84 & 5127.44 & 446.71 & 85.11 \\
\hline & $300 / 370$ & 52 & 1011.29 & 4008.32 & 303.39 & 1202.50 & 402.00 & 86.60 \\
\hline & $400 / 480$ & 46 & 1959.00 & 4376.96 & 940.32 & 2100.94 & 177.24 & 94.09 \\
\hline \multirow{3}{*}{ GACP0746 } & $2 / 3$ & 52 & 271.00 & 2143.11 & 542.00 & 4286.22 & 170.00 & 94.33 \\
\hline & $300 / 370$ & 50 & 781.698 & 2346.09 & 234.51 & 703.83 & 369.49 & 87.68 \\
\hline & $400 / 480$ & 52 & 505.69 & 2828.12 & 242.73 & 1357.50 & 558.20 & 81.39 \\
\hline
\end{tabular}

${ }^{a}$ Effects of working volume on cordycepin production, adenine and residual adenine concentrations in different bioreactors with the supplement of additives for $C$. militaris strains.

${ }^{\mathrm{b}}$ Working volume was the volume of medium in different bioreactors, and was showed by the volume of medium / the volume of bioreactor $(\mathrm{v} / \mathrm{v})$.

${ }^{\mathrm{c}}$ Cultivation time was the time of the maximal cordycepin production.

${ }^{\mathrm{d}}$ The additives (adenine $1 \mathrm{~g} / \mathrm{L}$; glycine $16 \mathrm{~g} / \mathrm{L}$ ) were added to the medium at day 4,10 , and 30 .

${ }^{\mathrm{e}}$ Total content of cordycepin $=$ cordycepin production $(\mathrm{mg} / \mathrm{L}) \times$ working volume $(\mathrm{mL})$.

${ }^{\mathrm{f}}$ Utilization ratio of adenine $=(3 \mathrm{~g} / \mathrm{L}$-Residual adenine concentration $) / 3 \mathrm{~g} / \mathrm{L} \times 100 \%$.

\section{Discussion}

In this paper, different bioreactors, working volumes, and different strains of GACP08Y5, GACP08Y1 and GACP0746 were quantified for their abilities to produce cordycepin in static liquid culture. Cordycepin production, total content of cordycepin, adenine concentration, adenine utilization ratio, and cultivation time differed under the various conditions. The result shown that the cordycepin production increased gradually with cultivation time in control group and experimental group (Figure 1 to 12), and there were significant differences between and experimental set-ups. 5L-flasks containing $2 \mathrm{~L}$ and $480 \mathrm{~mL}$-cylindrical glass bottles containing 400 $\mathrm{mL}$ of media enhanced cordycepin production per unit volume for strain GACP08Y5, and strains GACP08Y1 and GACP0746 (Table 1). Maximum total cordycepin production per unit volume reached $4376.96 \mathrm{mg} / \mathrm{L}$ for $C$. militaris strain GACP08Y1 in $480 \mathrm{~mL}$-cylindrical glass bottles containing $400 \mathrm{~mL}$ medium at day 46. This is lower than previous reports $8570 \mathrm{mg} / \mathrm{L}$ (Das et al. 2009) and $14300 \mathrm{mg} / \mathrm{L}$ (Masuda et al. 2014). However, the total content of cordycepin (3939.26 mg) was higher than previous reports (857 mg (Das et al. 2009) and $2145 \mathrm{mg}$ (Masuda et al. 2014)). A higher value of $6011.66 \mathrm{mg}$ for $C$. militaris GACP08Y5 was achieved in 5 L-flask containing $2 \mathrm{~L}$ medium at day $40(3005.83 \mathrm{mg} / \mathrm{L}$ in per unit volume $)$. This is the highest report of cordycepin production in a single fermenter.

In this study, adenine $1 \mathrm{~g} / \mathrm{L}$, glycine $16 \mathrm{~g} / \mathrm{L}$ were added to the medium at day 4,10 , and 30 and clearly enhanced cordycepin production. These results were higher than previously reported (Das et al. 2009, Kang et al. 2014, Masuda et al. 2014, Masuda et al. 2007). This is an excellent method for improved production of cordycepin. Adenine concentration first increased, and later decreased in control group (Figure 1a to 12a). The adenine concentration decreased rapidly when adding adenine $1 \mathrm{~g} / \mathrm{L}$ and glycine $16 \mathrm{~g} / \mathrm{L}$ (Figure $1 \mathrm{~b}$ to $12 \mathrm{~b}$ ). Therefore, we suspect that adenine was first produced, and then cordycepin was biosynthesized with adenine by $C$. militaris in the control group. However, cordycepin was directly synthesized with adenine of additives by $C$. militaris in experimental group. The results show that exogenously supplied adenosine was effective significantly to cordycepin biosynthesis (Chassy \& Suhadolnik 1969). Previous research showed that glycine was good additive for increase cordycepin production (Das et al. 2009, Kang et al. 2012, Masuda et al. 2007). The glycine only as additive was added to medium in this study. We 
did not detect the change of glycine concentration.

In order to obtain higher total cordycepin content, we used different working volumes of media in different bioreactors. Previous studies have shown that dissolved oxygen (DO) concentration is a key factor in the media for cell growth and metabolite biosynthesis (Mao \& Zhong 2004), and was not only an important part of the respiratory chain, but also of metabolite composition (Xie et al. 2008). But there exist limit value of DO in the medium (Mao \& Zhong 2004). As shown in Figure 2 to 4 and Table 1, the production of cordycepin reduced gradually with increasing working volume of the medium from 2 to $4 \mathrm{~L}$ in $5 \mathrm{~L}-f$ lasks, and the total content of cordycepin increased slowly. The DO concentration in the media is considered under the limit value of DO (data not shown) (Kang et al. 2014, Masuda \& Sakurai 2006). The results suggest that the limit value of bioreactor and working volume are pivotal in large-scale production by static liquid culture.

In the present experiment, three different wild-type strains of $C$. militaris were studied for production of cordycepin. The ability to produce cordycepin differed between these strains (Table 1). Maximum cordycepin production of $4376.96 \mathrm{mg} / \mathrm{L}$ was obtained. However, it was obviously lower than previous reports (Das et al. 2009, Masuda et al. 2014). In previous report, high-energy ion beam irradiation was applied to obtain a mutant strain of $C$. militaris with a higher cordycepin production (Das et al. 2009), and the maximum cordycepin production was reached $14300 \mathrm{mg} / \mathrm{L}$ (Masuda et al. 2014). Therefore, Screening of the microbial strains was very important for the production of the metabolites.

Simultaneously, mechanism of cordycepin biosynthesis is the most important. Nevertheless, Up to now related gene expression of cordycepin biosynthesis and change of metabolic are still not explained reasonably. Lennon \& Suhadolnik (1976) consider that the formation of 3'deoxyadenosine (cordycepin) may proceed by a reductive mechanism similar to that for the formation of 2'-deoxynucleotides. The pur cluster which encodes the puromycin biosynthetic pathway was studied in Streptomyces alboniger, and the oxidation-reduction of 3'-OH for puromycin has been deduced according to similarities of results and to previous biochemical work by authors (Tercero et al. 1996). The result might provide much convincing evidence for the cordycepin biosynthetic pathway (oxidation-reduction of 3'-OH).

\section{Acknowledgements}

This work was jointly supported by the National Natural Science Foundation of China (No. 31460012), the Science and Technology Foundation of Guizhou Province (No. [2016]2863), and the Youth Foundation of Guizhou Academy of Sciences (No. [2014]07).

\section{References}

Aman S, Anderson DJ, Connolly TJ, Crittall AJ, Ji G, 2000 - From adenosine to 3'deoxyadenosine: development and scale up. Organic Process Research and Development 4, 601-605.

Chassy BM, Suhadolnik RJ, 1969 - Nucleoside antibiotics. IV. Metabolic fate of adenosine and cordycepin by Cordyceps militaris during cordycepin biosynthesis. Biochimica et Biophysica Acta (BBA)-Nucleic Acids and Protein Synthesis 182, 307-315.

Cunningham KG, Manson W, Spring FS, 1950 - Cordycepin, a metabolic product isolated from cultures of Cordyceps militaris (Linn.) Link. Nature 166 (4231), 949.

Das SK, Masuda M, Hatashita M, Sakurai A, Sakakibara M, 2008 - A new approach for improving cordycepin productivity in surface liquid culture of Cordyceps militaris using high-energy ion beam irradiation. Letters in Applied Microbiology 47, 534-538.

Das SK, Masuda M, Sakurai A, Sakakibara M, 2009 - Effects of additives on cordycepin production using a Cordyceps militaris mutant induced by ion beam irradiation. African Journal of Biotechnology 8, 3041-3047. 
De Silva DD, Rapior S, Fons F, Bahkali AH, Hyde KD, 2012 - Medicinal mushrooms in supportive cancer therapies: an approach to anti-cancer effects and putative mechanisms of action. Fungal Diversity 55, 1-35.

De Silva DD, Rapior S, Sudarman E, Stadler M, Xu J, Alias SA, Hyde KD, 2013 - Bioactive metabolites from macrofungi: ethnopharmacology, biological activities and chemistry. Fungal Diversity 62, 1-40.

Guo P, Kai Q, Gao J, Lian Z, Wu C, Wu C, Zhu H, 2010 - Cordycepin prevents hyperlipidemia in hamsters fed a high-fat diet via activation of AMP-activated protein kinase. Journal of Pharmacological Sciences 113, 395-403.

Hung YP, Wang JJ, Wei BL, Lee CL, 2015 - Effect of the salts of deep ocean water on the production of cordycepin and adenosine of Cordyceps militaris fermented product. Amb Express 5, 1-9.

Kang C, Wen TC, Kang JC, Meng ZB, Li GR, Hyde KD, 2014 - Optimization of large-scale culture conditions for the production of cordycepin with Cordyceps militaris by liquid static culture. The Scientific World Journal Article ID 510627.

Kang C, Wen TC, Kang JC, Qian YX, Lei BX, 2012 - Effects of additives and different culture conditions on cordycepin production by the medicinal fungus Cordyceps militaris (in Chinese). Mycosystema 31, 389-397.

Kim JR, Yeon SH, Kim HS, Ahn YJ, 2002 - Larvicidal activity against Plutella xylostella of cordycepin from the fruiting body of Cordyceps militaris. Pest Management Science 58, 713 717.

Lennon MB, Suhadolnik RJ, 1976 - Biosynthesis of 3'-deoxyadenosine by Cordyceps militaris. Mechanism of reduction. Biochimica et Biophysica Acta (BBA)-Nucleic Acids and Protein Synthesis 425, 532-536.

Mao XB, Zhong JJ, 2004 - Hyperproduction of cordycepin by two-stage dissolved oxygen control in submerged cultivation of medicinal mushroom Cordyceps militaris in bioreactors. Biotechnology Progress 20, 1408-1413.

Masuda M, Das SK, Hatashita M, Fujihara S, Sakurai A, 2014 - Efficient production of cordycepin by the Cordyceps militaris mutant G81-3 for practical use. Process Biochemistry 49, 181187.

Masuda M, Urabe E, Honda H, Sakurai A, Sakakibara M, 2007 - Enhanced production of cordycepin by surface culture using the medicinal mushroom Cordyceps militaris. Enzyme and Microbial Technology 40, 1199-1205.

Masuda M, Urabe E, Sakurai A, Sakakibara M, 2006 - Production of cordycepin by surface culture using the medicinal mushroom Cordyceps militaris. Enzyme and Microbial Technology 39, 641-646.

Pao HY, Pan BS, Leu SF, Huang BM, 2012 - Cordycepin stimulated steroidogenesis in MA-10 mouse Leydig tumor cells through the protein kinase C Pathway. Journal of Agricultural and Food Chemistry 60, 4905-4913.

Ramesh T, Yoo SK, Kim SW, Hwang SY, Sohn SH, Kim IW, Kim SK, 2012 - Cordycepin (3'deoxyadenosine) attenuates age-related oxidative stress and ameliorates antioxidant capacity in rats. Experimental Gerontology 47, 979-987.

Shrestha B, Han S, Sung J, Sung G, 2012 - Fruiting body formation of Cordyceps militaris from multi-ascospore isolates and their single ascospore progeny strains. Mycobiology 40, 100 106.

Sung GH, Hywel-Jones NL, Sung JM, Luangsa-Ard JJ, Shrestha B, Spatafora JW, 2007 Phylogenetic classification of Cordyceps and the clavicipitaceous fungi. Studies in Mycology 57, 5-59.

Tercero JA, Espinosa JC, Lacalle RA, Jiménez A, 1996 - The biosynthetic pathway of the aminonucleoside antibiotic puromycin, as deduced from the molecular analysis of the pur cluster of Streptomyces alboniger. Journal of Biological Chemistry 271, 1579-1590. 
Thomadaki H, Tsiapalis CM, Scorilas A, 2008 - The effect of the polyadenylation inhibitor cordycepin on human Molt-4 and Daudi leukaemia and lymphoma cell lines. Cancer Chemotherapy and Pharmacology 61, 703-711.

Wen TC, Kang JC, Hyde KD, Li GR, Kang C, Chen X, 2014a - Phenotypic marking of Cordyceps militaris fruiting-bodies and their cordycepin production. Chiang Mai Journal of Science 41, 846-857.

Wen TC, Li GR, Kang JC, Kang C, Hyde KD, 2014b - Optimization of solid-state fermentation for fruiting body growth and cordycepin production by Cordyceps militaris. Chiang Mai Journal of Science 41, 858-872.

Wen TC, Li MF, Kang JC, He J, 2012 - A molecular genetic study on fruiting-body formation of Cordyceps militaris. African Journal of Microbiology Research 6, 5215-5221.

Xie T, Fang HY, Zhu GB, Zhu GJ, 2008 - Effect of dissolved oxygen on glycerol production by Candida glycerinogenes (in Chinese). China Biotechnology 28, 65-70. 